\title{
Radiographic assessment of multiple pathoses and dental malocclusion: a case study
}

SADJ April 2019, Vol. 74 No. 3 p 123 - p125

V Soni', B Buch ${ }^{2}$, D Kotsane ${ }^{3}$

\section{ABSTRACT}

Odontomas are rare pathological abnormalities which may occur at any age. It is most unusual to observe an odontoma together with supernumerary teeth, more particularly if this is found in conjunction with an osteoma. This report emphasizes the underlying pathology of a case co-incidentally encountered in a 14 year old patient whose main complaint was of a painful 85 tooth.

An incisional biopsy of the area revealed the presence of mineralized tooth-related tissue resembling a complex odontoma. In conjunction with the radiographic evidence, which confirmed the presence of complex and compound odontomas as well as a number of small osteomas, a provisional diagnosis of Gardner's syndrome was made. The syndrome is a rare autosomal disease that is difficult to treat. If a dentist suspects a patient may present with Gardner's syndrome, the patient should be referred immediately for further medical management.

\section{INTRODUCTION}

Benign odontogenic tumours include ameloblastoma, ameloblastic fibroma, ameloblastic fibrodontoma, complex and compound odontomas. ${ }^{1}$ Of these, the most commonly encountered in patients less than 20 years of age are the complex and compound odontomas. ${ }^{2}$ These tumours are asymptomatic, slow- growing and may lead to malformation of adjacent developing teeth and malocclusion.

The complexity of odontomas has been studied and analyzed for many years. One example is that of supernumerary teeth developing largely within the maxillary permanent dentition and in conjunction with odontomas. ${ }^{3}$ These are usually asymptomatic, but may be associated

\section{Author affiliations:}

1. Vishani Soni: BChD (Pret), MSc (Dent)(Wits), Department of General Dental Practice, School of Oral Health Sciences, University of the Witwatersrand, Johannesburg.

2. Brian Buch: BSc (Hons) (Natal); SED (UCT); BDS (Wits); MSc (Dent) (Wits), Emeritus Professor-University of Pretoria, Visiting Professor and Part-time Consultant: Division of Maxillo-Facial and Oral Radiology, Department of General Dental Practice, School of Oral Health Sciences, university of the Witwatersrand, Johannesburg.

3. Daisy Kotsane: BDT, BDS (Medunsa), PDHE (Pret), MBA (RSB), Head, Dept. of General Dental Practice, School of Oral Health Sciences, University of the Witwatersrand, Johannesburg, South Africa. Corresponding author: Vishani Soni

Department of General Dental Practice, School of Oral Health Sciences,

University of the Witwatersrand, Johannesburg, South Africa.

Email: vishani.soni@wits.ac.za with pathologic implications. One such manifestation is that of Gardener's Syndrome if the odontoma is also associated with the presence of osteomas. ${ }^{4-10}$ This is a life-threatening condition and it is essential that the presenting signs are not missed.

\section{CASE REPORT}

A 14 year-old female patient presented at the Wits Oral Health Centre complaining of a painful primary tooth (85) which appeared to have prevented eruption of the permanent successor, causing a severe malocclusion.

No medical problems were reported. Extra-oral findings revealed no abnormalities. Facial asymmetry was not detected (Fig 1). Intra-oral examination revealed missing premolars together with carious and painful mandibular primary second molars (Figs 1-5). An anterior cross bite involving tooth 42 was noted together with a deep overbite (Fig 2). The gingiva surrounding the painful tooth (85) was swollen with a buccal exudate (Fig 4).
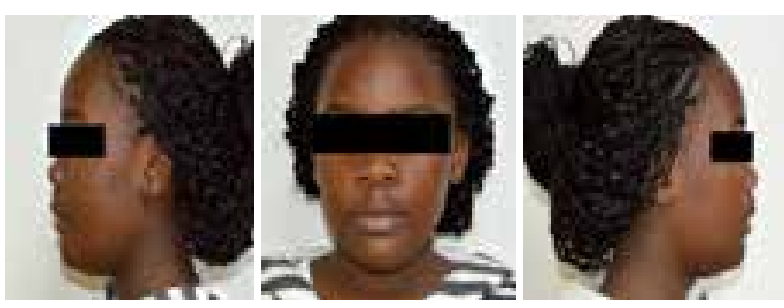

Figure 1. The patient: left, frontal and right views.

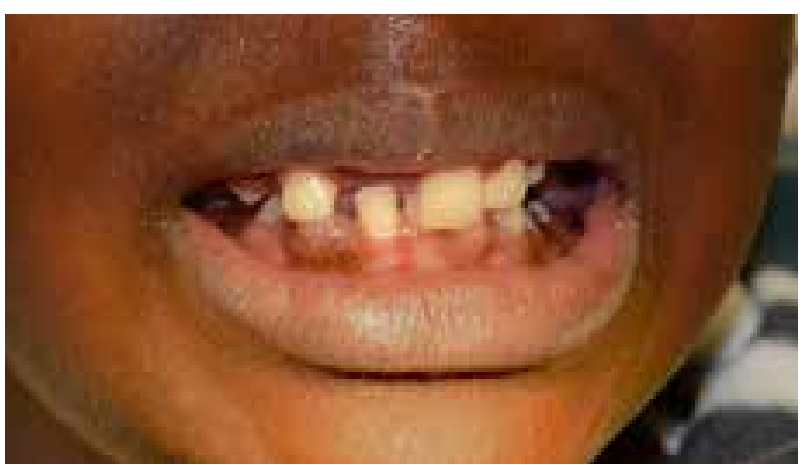

Figure 2. The occlusion with the 42 tooth in crossbite position.

In pursuit of accurate diagnosis and an appropriate treatment plan, further investigations included a panoramic radiograph, a lateral cephalogram and a cone-beam volumetric tomogram (CBCT). 


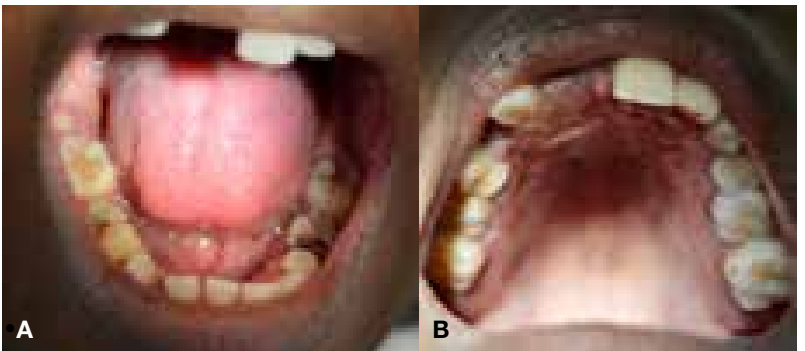

Figure 3. Occlusal views: (A) Mandible and (B) Maxilla.

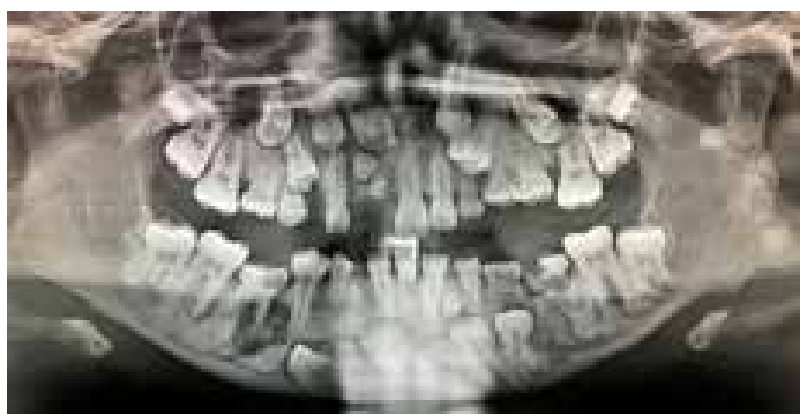

Figure 4. Panoramic radiograph showing a radicular cyst on tooth 85 and multiple odontomas.

The panoramic radiograph revealed the presence of numerous unerupted and retained deciduous teeth, compound and complex odontomas (bi-mandibular) and a well circumscribed radiolucent lesion resembling a radicular cyst at the apex of the right mandibular deciduous second molar tooth. Several of the unerupted teeth were supernumeraries. The angles of the mandible were deformed by presence number of ectopic teeth and small osteomas (Fig 4). The lateral cephalogram revealed a growth on the inion of the occipital bone (Fig 5).

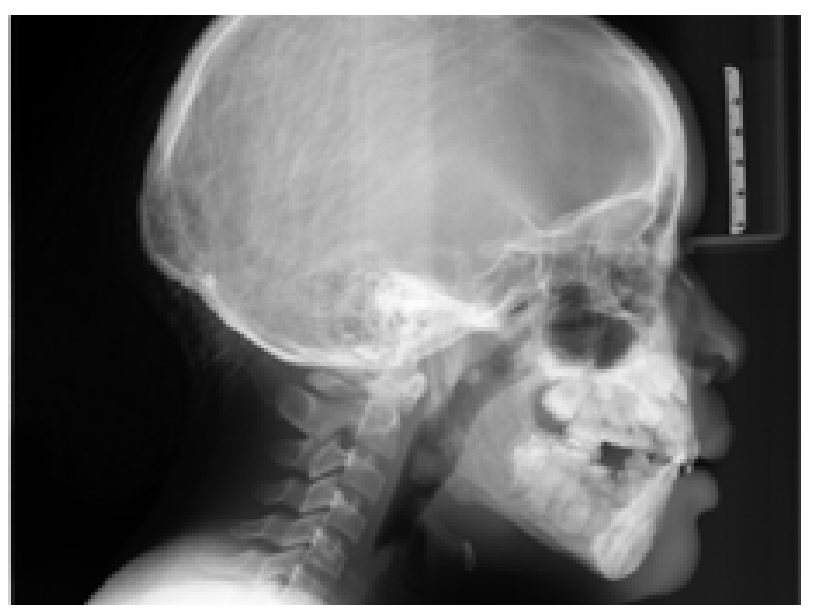

Figure 5. Cephalometric radiograph showing a growth over the area of the inion.

The patient was classified as having a normal skeletal and dental class 1 profile (Fig 5). However, the bone deformities together with the presence of unerupted supernumeraries, ectopic teeth, osteomas and compound and complex odontomas suggested a diagnosis of Gardner's syndrome, despite the apparent absence of visible epidermoid cysts of the skin.

The CBCT scan confirmed the presence of carious lesions of the teeth, together with multiple radio-opacities on the left angle and ramus of the mandible (Fig 6).
These displayed the appearance of osteomas, thereby confirming the provisional diagnosis of Gardner's syndrome.
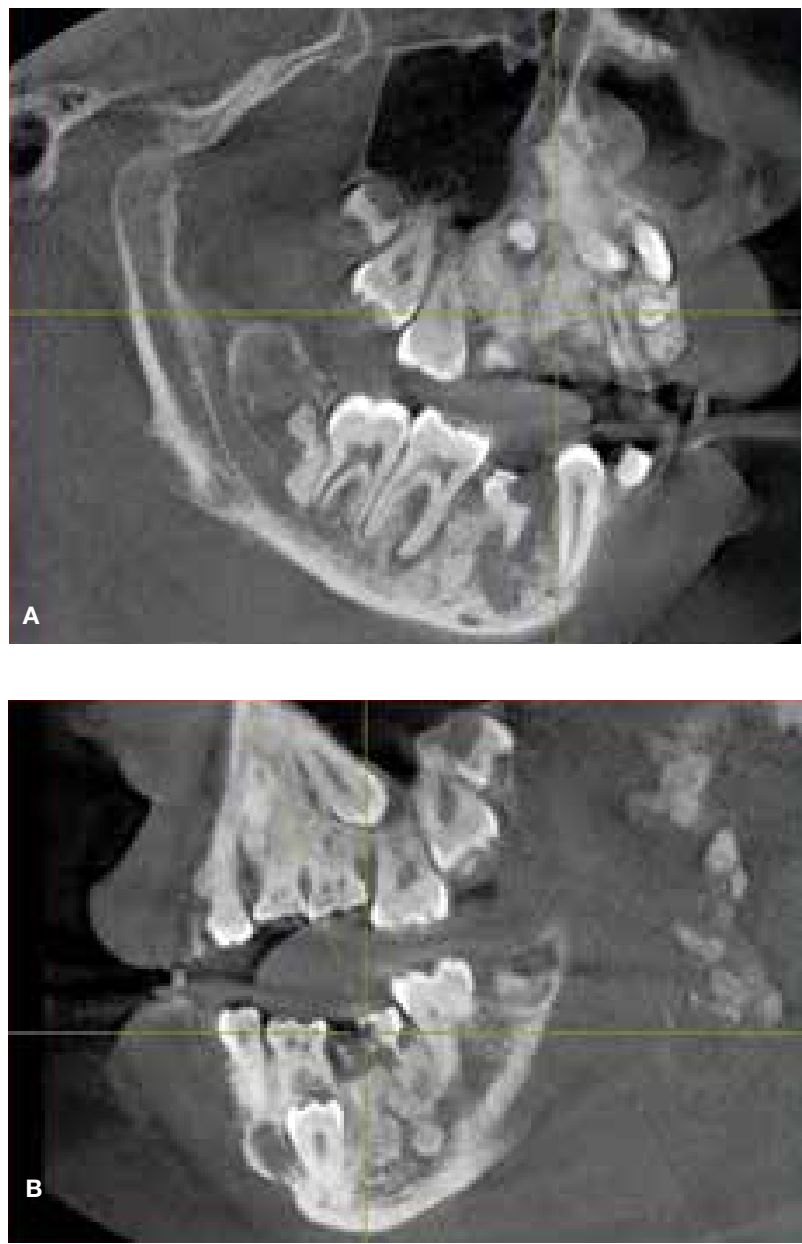

Figure 6. CBCT analysis in tangential view of the right side $(A)$ and $(B)$ left side of the jaw.

An incisional biopsy was done on the right mandible at which the affected tooth and several fragments of bone were removed for microscopic examination. The latter revealed mineralized tissue, trabeculae of woven and lamellar bone together with fragments of enamel.

\section{DISCUSSION AND CONCLUSION}

The large number of supernumerary and ectopic teeth together with mixed odontomas and osteomas ${ }^{3-11}$ may be regarded as a rare occurrence.

Based on the clinical, radiological and biopsy findings, a diagnosis of Gardner's syndrome is justified. This is arare autosomal disease characterised by intestinal polyposis, connective tissue tumours and multiple osteomatosis. ${ }^{3,5-9,12}$ The malignant potential of the intestinal polyps, the presence of which the patient is totally unaware, makes it essential for a dentist to be aware of the signs for early detection of the condition. ${ }^{12}$

Treatment entailed surgical excision of the odontomas and enucleation of the cyst for aesthetic reasons. Thereafter fixed orthodontic appliance treatment would be considered when complete healing occurred. 
Referral for colonoscopy was essential for final confirmation of Gardener's Syndrome and the surgical removal of colonic polyps. Recurrence of the odontomas and osteomas is not uncommon and would require possible further surgical intervention. Since there is no cure for Gardner's Syndrome, prevention of cancer is the primary aim in management. ${ }^{12}$

\section{Acknowledgement}

Sincere thanks to Professor E Rikhotso and his team from the Maxillo-facial and Oral Surgery Department for sharing the biopsy information with us. The authors would also like to thank Professor Dandajena, Dr Moshaoa and Professor Evans of the Orthodontic Department for their opinion on the orthodontic treatment approach of this case.

\section{References}

1. Gyulai-Gaál S, Takács D, Barabás J, Tarján I, Martonffy K, Szabó G, Suba Z. Mixed odontogenic tumor in children and adolescents. Fogorv Sz. 2007; 100(2):65-9.

2. De Oliveira BH, Campos V, Marçal S. Compound odontomadiagnosis and treatment: three case reports. Ped Dent. 2001;23:151-7.

3. Pippi R. Odontomas and supernumerary teeth: is there a common origin? Int J Med Sci. 2014;11:1282.

4. Gaynor WN. Bilateral radicular cysts of mandibular deciduous teeth: a case report. New Zealand Dent J. 2012; 108:106-9.

5. Oner AY, Pocan S. Gardner's syndrome: A case report. BDJ.2006; 200; 666-7.

6. Panjwani S, Bagewadi A, Keluskar V, Arora S. Gardner's Syndrome. J Clinic Imaging Sci. 2011; 4: 1-4.

7. Seehra J, Patel S, Bryant C. Gardner's Syndrome revisited: clinical case and overview of the literature. J Orthodontics. 2016:43; 59-64.

8. Fonseca LC, Kodama NK, Nunes FC, Maciel PH, Fonseca FA, Roitberg M, de Oliveira JX, Cavalcanti MG. Radiographic assessment of Gardner's syndrome. Dentomaxillofacial Rad. 2007; 36: 121-4.

9. Koh KJ, Park HN, Kim KA. Gardner syndrome associated with multiple osteomas, intestinal polyposis, and epidermoid cysts. Imag. Sci Dent. 2016; 46:267-72.

10. Chung EH, Sun H, Yang YI, Yun SH, Jeon MK. Peripheral osteoma in the mandibular angle. Arch Plastic Surg. 2015;42:798.

11. Astekar M, Manjunatha BS, Kaur P, Singh J. Histopathological insight of complex odontoma associated with a dentigerous cyst. BMJ case reports; 2014:bcr2013200316.

12. Adisen MZ, Okkesim A, Misirlioglu M. The importance of early diagnosis of Gardner's syndrome in dental examination. Nige J Clinic Prac. 2018;21:114-6.

\section{Do the CPD questionnaire on page 153}

The Continuous Professional Development (CPD) section provides for twenty general questions and five ethics questions. The section provides members with a valuable source of CPD points whilst also achieving the objective of CPD, to assure continuing education. The importance of continuing professional development should not be underestimated, it is a career-long obligation for practicing professionals.

\section{Online CPD in 6 Easy Steps}

Go to the SADA website www.sada.co.za.

Log into the 'member only' section with your unique SADA username and password.

Select the CPD navigation tab.

Select the questionnaire that you wish to complete.

Enter your multiple choice answers. Please note that you have two attempts to obtain at least $70 \%$.

View and print your CPD certificate. 